\title{
Adapting by Altering: Spatial modifications of terraced houses in the Klang Valley area
}

\author{
Erdayu Os'hara Omar, Esmawee Endut, Masran Saruwono \\ Faculty of Architecture, Planning \& Surveying \\ Universiti Teknologi MARA, Malaysia \\ erdayu24@salam.uitm.edu.my
}

\begin{abstract}
This paper presents the initial findings of a study on the spatial modifications of fifty houses by homeowners in the Klang Valley area. Using a standardised format, various attributes consisting altered spaces and features were compiled and examined. It appears that certain features of the houses including kitchen, bedrooms and bathrooms were desperately altered. People have used their creativity in altering the spaces beyond the original intentions of the architect. To some extent, the findings indicate that the current model for providing houses has shortcomings in addressing the need to satisfy the aspirations of individual family to living.
\end{abstract}

Keywords: modification, alteration, personalization, systematic observation, adaptation

eISSN 2514-751X @ 2017 The Authors. Published for AMER ABRA by e-International Publishing House, Ltd., UK.. This is an open access article under the CC BY-NC-ND license (http://creativecommons.org/licenses/by-ncnd/4.0/). Peer-review under responsibility of AMER (Association of Malaysian Environment-Behaviour Researchers), ABRA (Association of Behavioural Researchers on Asians) and $c E-B s$ (Centre for EnvironmentBehaviour Studies), Faculty of Architecture, Planning \& Surveying, Universiti Teknologi MARA, Malaysia.

https://doi.org/10.21834/aje-bs.v2i2.173 


\subsection{Introduction}

Over the past forty years Malaysia has seen a rapid construction of terraced housing developments all over the country. The terraced houses are a type of mass housing initiative, developed by either the government of private developers in the country, in order to meet the ever increasing demand for housing. Also known as "row house" in some countries, it was adopted from the British terraced house design (Hashim, Rahim, Rashid \& Yahaya, 2006). In general, terraced house is relatively narrow and deep with fenestration at the front and back (Chandler et al., 2005). Typical layout according to Hashim \& Rahim (2008) consists of rows of rectangular housing lot where boundaries are clearly defined by using chain-linked fence or brick perimeter wall, featuring repetitive and monotonous designs.

The common spatial characteristics of the terraced houses in Malaysia have not changed much ever since. In order to confirm this, examination of sales brochures from current housing developments from all over the country was carried out. Generally most terraced house has a minimum of three bedrooms, one utility room, three bathrooms, combined living and dining room and a kitchen at the back. Storage area is commonly located under the staircase. On the first floor, layout has not changed much since the last forty years. Master bedroom with its attached bathroom is usually located at the front with two other bedrooms, which share a bathroom, facing the back. A small family hall is placed in the centre, connecting all the bedrooms with the staircase to the floor below. A car porch is provided outside, which could accommodate at least one car at the front with a small terrace facing the front yard. In the recent past, property developers seemed to have upgraded chain-link fences whereby brick perimeter wall were quite commonly provided instead.

\section{0 Literature Review}

\subsection{Adapting To Mass Housing}

The mass housing design initiatives has its strength and weaknesses. While it offers a reasonable alternative of housing needs for the general population, it certainly not what everyone aspired. For instance, the solution of "one design fits all" could not accommodate individual's specific needs. Ozaki (2002) points out that mismatch between house design and the user's values and lifestyle will lead to dissatisfaction. This is a gap what Tipple (2000) considers as "housing stress". Bell et al. (2001) finds that when a certain attributes become inadequate, a coping response is used. Coping response may or may not be successful. Successful coping leads to a process called adaptation. Residents may adopt passive or active adaptation. Passive adaptation refers to self adapting of the resident themselves. For example, residents would just manage around the inadequate kitchen. Active adaptation refers to physical modification to address the stressor. Small kitchen were 
enlarged, bedrooms were added to solve the inadequacy of number of bedrooms. Unsuccessful coping leads to continuation of stress which may lead to inability to cope, and decrease of performance of activities.

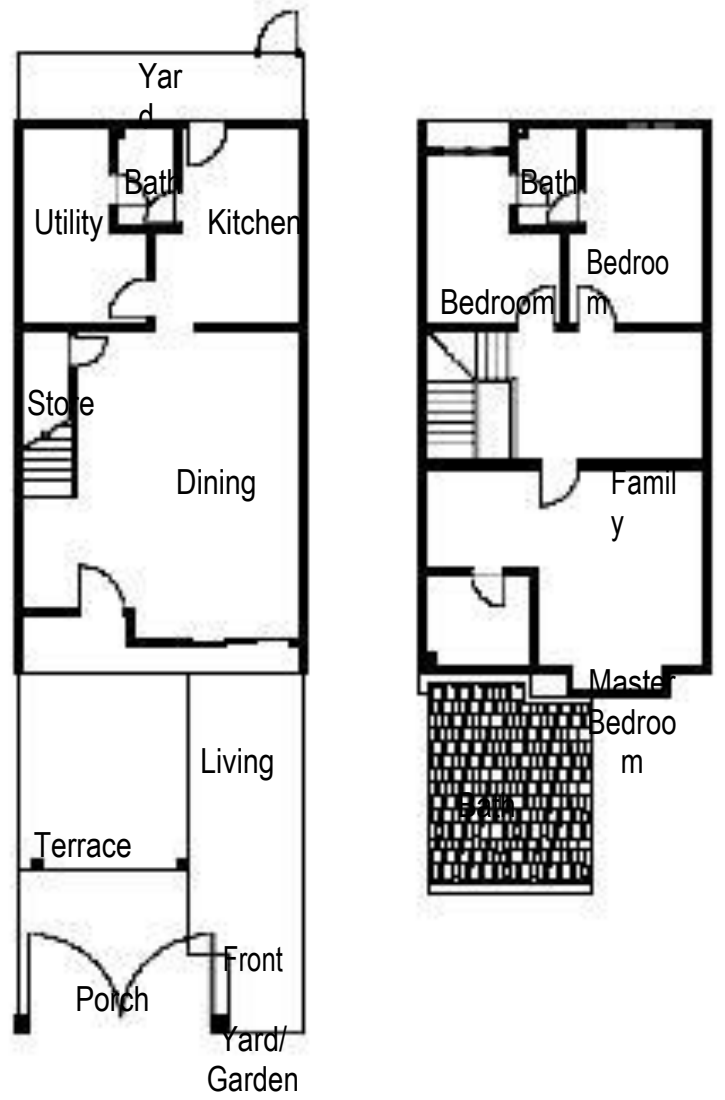

Figure 1: Typical floor plan of an intermediate unit of a terrace house in Malaysia

\subsection{Comfort in the Context of Home Environment}

Whereas the house is a physical structure where people reside, home is a psychological concept carrying rich cultural, demographic and psychological meanings (Gifford, 1997). The home provides a sense of warmth and comfort, safety and security to the occupiers. Above all, the home provides a venue for self-expression and a portrayal of identity of the owners (Kopec, 2006). 
The study of office environment by Vischer (2007) will probably be useful in describing the concept of "comfort". Vischer has categorised comfort in three levels namely; physical, functional and psychological. In addition, Vischer regards anything below the threshold level as "discomfort". Her conception is illustrated in what she calls the "Habitability Pyramid" (Fig. 2). Physical comfort emerges upon overcoming "discomfort" as one is sheltered from the physical threat from the elements and where other simple human activities which are met for a home to be habitable. Functional comfort focuses on making spaces performing effectively for certain activities and functions. At the top of the pyramid is the psychological comfort which relates to personal conception on living and the person's social position in the context of the larger society. Therefore, it may be said that to certain section of the society, comfort can only be achieved when these needs are met. The nature of human beings is that once the basic need has been fulfilled, one aspires to achieve a higher level of self-fulfilment.

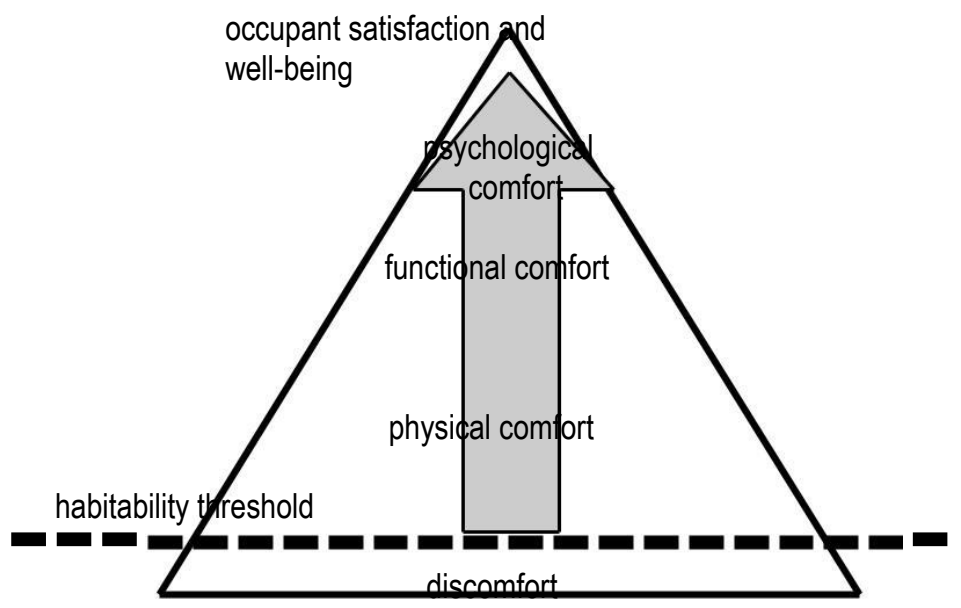

Figure 2: Habitability Pyramid showing relationship of environmental comfort Source: (Vischer, 2007)

\subsection{Methodology}

The double storey terraced houses comprised the majority of house type built and the most popular form landed property in the country. Fifty samples were selected from privately developed urban housing development scattered across the Klang Valley. As only homeowners may make physical modification to the house (Marcus \& Sarkissian, 1986), only owner-occupied properties were chosen. They were selected through property listing which were advertised over a period of six months. Owner-occupied houses will allow the researcher to observe the physical trace and study how the spaces in the homes were 
used. Another important selection criterion is that the property must have been modified or renovated. Unmodified homes were filtered out by screening the descriptions of the property in the listing and advertisements. Descriptions must contain words such as "modified", "extended", "renovated" and any other words which indicate physical changes have been made to the house.

This paper focus only on interior changes made to the home. It was decided that the best method for this study was observation and informal interview. The initial difficulty in this investigation was lack of cooperation from both estate agents and homeowners. Due to that, the researcher responded to advertisements as a potential buyer. This technique was similar to previous work carried out by Coupe and Morgan (1981). A standardized format sheet was devised to record the observation process. It covers various attributes of the house ranging from spatial modification, components and features modification (the format sheet is available upon request). Interview was found to be very informative as the homeowner will not only give a brief history and descriptions of the modifications but also give glimpse into their life, how family activities are carried out and how do they attend to the guest. The descriptions were all digitally recorded to assist the researcher in analysis. Photographs of any physical changes made to the home were also taken whenever allowed.

\subsection{Extent Of Renovation}

An immediate observation indicates there is a possibility that altering the home is important for people. Previous studies suggested there is a connection between adaptation and creation of a home. It was discovered that houses provided by housing developers achieved the basic physical comfort needed. However, modification was made to improve and achieve the desired functional and psychological comfort. The results show that homes went through spatial alteration with a mean of 6.54 and it is a very significant finding. This strengthens the notion that personalization is an approach in creating a home.

It is common knowledge that kitchen is one of the favourite renovated spaces in local housing development. Findings have confirmed that kitchen has been very significantly modified. Nearly all of the houses added a "wet kitchen" to facilitate cooking and washing (Fig. 3). This finding support previous research carried out by Sazally, Omar et al. (2010) where homeowners found there is a crucial need for a bigger kitchen and a separate "wet kitchen". The former kitchen was transformed into a "dry kitchen" and was installed with built-in kitchen cabinets. Most homeowners pointed out that the dry kitchen was only used for warming up food (using the oven) and functions more to impress guests, as indication of their status.

Bedrooms are another feature which is commonly modified. The data shows that a total of 51 modifications were observed. Enlargement or additional new bedrooms suggests there is a need for more space to accommodate a growing household. In order to improve privacy, homeowners aspire to have more bedrooms. Adding new bedrooms requires sacrificing a space which must be available at the first place. Most bedrooms were added or 
enlarged by sacrificing the family room. From the informal interview with the homeowners, it was discovered that lack of privacy due to bedroom shortage is one of reasons they were looking for a bigger house.

Most modifications on terrace involved in removal of the space (40\%) while $26 \%$ had increased the size of terraces by extending and adding new terraces. The finding suggests terraces were "sacrificed" for other purposes. All of the terraces were removed as homeowners find there is a need for bigger living room which is normally connected to it (Fig. 4) An enlarged living room allows homeowner to create two sitting area. Surprisingly, storage appears to be of least important. From the visit, it seems there is lack of storage space available for the homeowners. Majority of the homes used part of utility room or sacrificed part of the smallest bedroom for storage. Only six cases created additional storage room while four cases are without storage room at all. When asked on the lack of storage space, all of the homeowners did not comment negatively but informed that they are willing to give up a portion of bedroom space for storage purposes

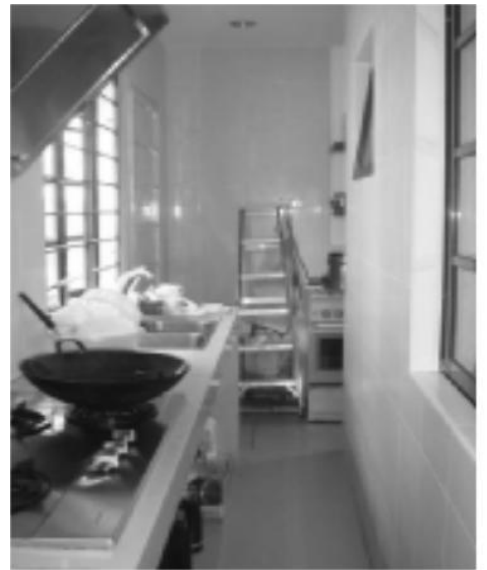

Figure 3: Examples of modification made on kitchen by homeowners

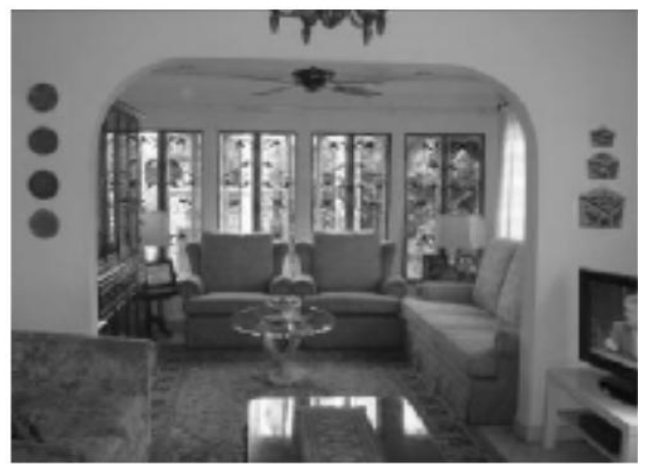

Figure 4: Terrace altered into a "second" living room

Certain spaces were added to the home by homeowners to satisfy particular functions and needs. Having a guest bedroom is considered as luxury due to limited space. Guest bedroom usually was a former utility room which was enlarged and transformed into a bedroom. This shows for certain homeowners, it is important to have a spare bedroom as it provides better privacy for visiting guests. There are four cases of a maid's room being added when utility room was used for other function such as a bedroom or family room. TV room and prayer room were also added with three and two cases each. It can be assumed that this reflects on the homeowners psychological needs. Figure 5 below summarizes the frequency of spatial modifications found during the survey. 


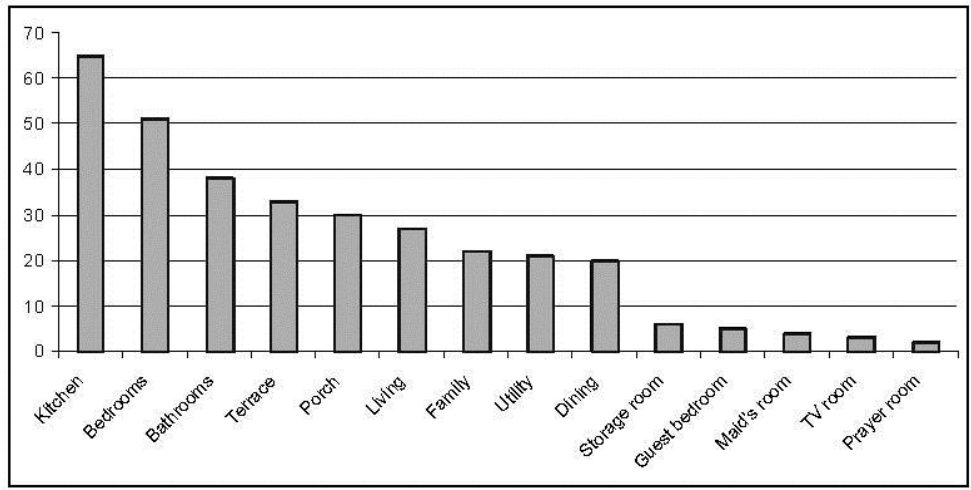

Figure 5: Frequency of alteration of features in houses

\subsection{Process Of Renovation}

The three most common possibilities where alteration of features can take place are by extension, reduction and relocation. Where spaces are available and permissible, extending the house is much desired. Reduction in the size of the space through division or removal of space is carried out to make adjustments for individual functional needs. Relocation of certain features occurs on optimizing certain features in alteration process which does not affect the built-up area of the house.

Changes to increase floor area suggest that there is lack of space available in the house. It also suggests that the former condition of the house was inadequate for certain activities to be carried out. Increase in floor area also implies there is an attempt to improve privacy. More bedrooms mean less shared bedrooms among the residents. Additional rooms also create better performance for specific function like for a home-office, study area or library. Extension attempts at acquiring available space or sacrificing another room. When space is available, creating additional room is an option. The data shows that extension is the preferred approach compared to addition. It can be assumed that this is due to limited spaces which cannot accommodate an addition of new room or for economical reasons. A total of $22 \%$ (11 cases) did not add new rooms or space to their home. The number of spaces added per house range between one to six spaces. From the study, it was found that cases where wet kitchen were added have been highly significant $\left(x^{2}=25.920, p<.0001\right)$.

It is not uncommon for modification to decrease the floor area. This type of upgrade implies that there are spaces which are not needed or certain lower level of importance. It can be seen when a space was "let go" for another use. A common space which was found to be usually "sacrificed" is the back yard. Transforming the backyard into part of the kitchen allows the kitchen to be enlarged and this also suggested that there is less important need for a backyard to the homeowners. Another alternative approach is through 
relocation of spaces. Employing this method suggest that the former location is unsuitable for the particular activities carried out. This also suggests the space was of lesser importance and had to be sacrificed for a space of a higher priority. Implication of this method is the total built up area of the home remains the same. Some may view that this method is more economical compared to other method as it effects only the change of function of the space.

\subsection{Discussion}

This paper is intended to report the initial findings of ongoing research which attempts to explore how contemporary terraced houses were altered by the occupants themselves. One of the findings from this study is that alteration can be tracked down and recorded. Renovation is one of the methods employed by homeowners to personalize their home. Six distinct approaches were found which are extension, addition, reduction, division, removal and relocation. People tended to make extensions of their terraced houses at every opportunity available.

Home is not just a place of shelter but it has rich meanings, provides warmth, comfort and security to the residents. Renovation was made to improve functional and psychological comfort, which are the basic human needs. This confirms to what Nalkaya (1980) has established that major changes made were the result of changes in the basic human needs. The evidence from this study also suggests that there may be a mismatch between what has been provided in current house design, requirements and needs by homeowners with the alterations made to the house. Number of bedrooms was found to remain even after extensive modifications although there was a need for additional bedroom. Findings from the survey indicated that household which is moving finds their current home to be inadequate for their current lifestyle. However, it is still premature to conclude the findings. Terrace house remain as one of the most popular form of landed property and even with limited scope for physical modification, renovations are still being carried out to fulfil the homeowner' needs.

\subsection{Conclusion}

This paper is intended to report the initial findings of ongoing research which attempts to explore how contemporary terraced houses were altered by the occupants themselves. One of the findings from this study is that alteration can be tracked down and recorded. Renovation is one of the methods employed by homeowners to personalize their home. Six distinct approaches were found which are extension, addition, reduction, division, removal and relocation. People tended to make extensions of their terraced houses at every opportunity available. 
Home is not just a place of shelter but it has rich meanings, provides warmth, comfort and security to the residents. Renovation was made to improve functional and psychological comfort, which are the basic human needs. This confirms to what Nalkaya (1980) has established that major changes made were the result of changes in the basic human needs. The evidence from this study also suggests that there may be a mismatch between what has been provided in current house design, requirements and needs by homeowners with the alterations made to the house. Number of bedrooms was found to remain even after extensive modifications although there was a need for additional bedroom. Findings from the survey indicated that household which is moving finds their current home to be inadequate for their current lifestyle. However, it is still premature to conclude the findings. Terrace house remain as one of the most popular form of landed property and even with limited scope for physical modification, renovations are still being carried out to fulfil the homeowner' needs.

\section{Acknowledgement}

We would like to acknowledge and extend our heartfelt gratitude to Universiti Teknologi MARA (UiTM) for the financial assistance in funding our research.

\section{References}

Bell, P. A., Greene, T. C., Fisher, J. D., \& Baum, A. (2001). Environmental Psychology (Fifth ed.). Belmont CA: Wadsworth Group.

Chandler, R., Clancy, J., Dixon, D., Goody, J., Wooding, G., \& Lawrence, J. (2005). Building type basics for housing. New Jersey: John Wiley \& Sons.

Coupe, R. T. \& Morgan, B. S. (1981). Towards a fuller understanding of residential mobility: a case study in Northampton, England. Environment and Planning A, 13, 201-215.

Gifford, R. (1997). Environmental Psychology: Principles and Practice. MA: Allyn \& Bacon.

Hashim, A. H., \& Rahim, Z. A. (2008). The Influence of Privacy Regulation on Urban Malay Families Living in Terrace Housing. International Journal of Architectural Research, 2(2), 94-102.

Hashim, A. H., Rahim, Z. A., Rashid, S. N. S. A., \& Yahaya, N. (2006). Visual privacy and family intimacy: a case study of Malay inhabitants living in two-storey low-cost terrace housing. Environment and Planning B: Planning and Design, 33, 301-318.

Kopec, D. (2006). Environmental psychology for design. New York: Fairchild Publications Inc.

Marcus, C. C., \& Sarkissian, W. (1986). Housing as if people mattered: Site design guidelines for medium-density family housing. Berkeley and Los Angeles, California: University of California Press. 
Nalkaya, S. (1980). The Personalization of a Housing Environment: A Study of Levittown, Pennsylvania Unpublished Ph.D., University of Pennsylvania, United States - Pennsylvania.

Ozaki, R. (2002). 'Mind The Gap': Customers' Perceptions and the Gaps Between What People Expect and What They Are Offered. In Consumer Choice in Housing. York: The Joseph Rowntree Foundation.

Saruwono, M. (2007). An analysis of plans of modified houses in an urbanised housing area of Malaysia. Unpublished Ph.D, The University of Sheffield.

Sazally, S. H., Omar, E., Hamdan, H., \& Bajunid, A. F. I. (2010). Modification trends of terrace houses: A case study of Section 7, Shah Alam, Selangor. Asian Journal of Environment-Behaviour Studies, 1(1), 47-62.

Tipple, G. (2000). Extending Themselves: User-Initiated Transformations of Government-Built Housing in Developing Countries Liverpool, England: Liverpool University Press.

Vischer, J. C. (2007). The concept of environmental comfort in workplace performance.Ambiente Construido, Porto Alegre, 7(1), 21-34. 